\title{
International Logistics Development under Economic Background of New Silk Road
}

\author{
Ning Luo \\ Xi'an International University, Xi'an, Shaanxi, 710077, China
}

Keywords: New Silk Road, International logistics, Development, Analysis

\begin{abstract}
The flourish of modern logistics has created profits for enterprises for the third time. Internationalized logistics and trade are the inevitable direction of modern logistics. Moreover, the construction of international logistics center can promote the rapid development of international trade due to gradual rising of the status of China in international affairs. Economic Belt of New Silk Road prepared by China for construction aims at developing the Great Northwest and promoting the trade with Central Asia and Europe through the development of this New Silk Road. This paper analyzes international trade under the background of New Silk Road on this basis.
\end{abstract}

\section{Introduction}

Logistics management and service of supply chain are the basic supply chain organization of modern industry development. Industry clustering becomes a feature of modern industry. The construction of modern logistics system is especially important in the construction of Economic Belt, which is good for dredging international logistics channel and can impel industries of close relationship with logistics to gather in the hub and node of main economy and industries on the Silk Road. This practice can improve economic cooperation ability of countries and regions on the Silk Road and make it possible to form a close cooperation mechanism and mutually beneficial economic and industrial development relation. Moreover, hub cities with cluster industrial development and sustainable growth functions on the Economic Belt of Silk Road can be cultivated through the construction of logistics system. This has profound significance for the construction of Economic Belt of Silk Road.

\section{Logistics industry development planning of hub cities on Silk Road}

Due to the special significance of the construction of logistics system on the Economic Belt of Silk Road for the development of the whole Silk Road plus the important role of hub and node cities of logistics on the Economic Belt in international and domestic economic cooperation, it is necessary to integrate international and domestic resources, focus on the construction and cultivation of logistics hub cities on the Economic Belt of Silk Road and make the Economic Belt of Silk Road play a role in the development of western regions as soon as possible. Therefore, a clear and detailed strategic plan is made for the development of logistics in hub cities.

Important significance of logistic development planning of hub cities. The creation of Economic Belt of New Silk Road has formed city agglomerations with a considerable scale in the territory of China, including Guanzhong, upstream of Yellow River, Hexi Corridor, northern Xinjiang, southern Xinjiang, north-central Harbin, Fergana Valley and surrounding cities and Ili river valley - southeast Harbin city agglomerations. The central city in each city agglomeration plays a special role in industrial distribution and economic development of Economic Belt. Meanwhile, each central city on the Economic Belt of Silk Road should form a close relation of economic division and industrial development so that city agglomerations can complement each other. The orientation of logistics development in each central city should be based on logistics efficiency and cost advantage and meanwhile consider interactive and integrated development advantages of logistics and relevant industries so as to place functions of each central city in the Economic Belt most reasonably, accelerate the construction speed of hub cities on the Economic Belt, exert functions of each central 
city in the construction of Economic Belt of Silk Road and allow logistics service system to release its potentials.

Orientation of logistics development in hub cities. Strategic positioning of logistics development in hub cities is based on traffic location, industrial base and accumulation ability of factors and aims at making industrial development mode and contents more consistent with the practical situation of cities. Therefore, it is required to focus on regional radiation scope of logistics service and its matched service functions during the positioning of logistics service of hub cities, and meanwhile develop relevant industries with logistics service environment and conditions so as to make logistics and relevant industries develop interactively and jointly and establish strategic positioning of central cities from multiple perspectives.

a). Orientation of area radiation. Differences of radiation space in different cities are determined by logistics efficiency and cost. Each central city should determine its radiating development direction of logistics from four major perspectives and specify the area radiation direction of Economic Belt of Silk Road so as to determine contents of industrial development based on area radiation scope. It is required to improve competitive advantages different from other cities in the construction of Silk Road.

b). Positioning of hub function. Due to different radiation scopes of logistics and factors such as traffic facility, network condition and transportation efficiency, logistics service system of each central system has formed different functions. Each central city should position itself according to its own location radiation, improve logistics infrastructure and functions of logistics service organization of the Economic Belt of Silk Road, focus on cultivating its core logistics service functions and promote the formation and development of core competitiveness.

c). Positioning of industrial development. Logistics hub functions should be exerted so that each central city forms its own characteristics and abilities in industrial distribution and cultivation. Each central city has its own resource features and industrial base and should position its logistics industry and closely related goods trade and international trade. Such practice can help central cities in industrial transformation and promote the extension and development of competitive tertiary industry.

\section{Development path of close connection between logistics and relevant industries on Economic Belt of Silk Road}

To form an intensive and large-scale logistics development environment on the Economic Belt of Silk Road, it is required to cultivate and construct logistics hub cities, explore the close relation between logistics and relevant industries in central cities according to the development of logistics and relevant industries in hub cities and seek for a development path of tertiary industry.

Basic thinking on connection and development of logistics and relevant industries. It is required to achieve interactive development of modern logistics and other industries, take the development path of organic linking of industries and realize the innovation of development mode and industrial distribution under the condition of new era. However, its basic thinking should be based on the construction of Economic Belt of Silk Road. Industry selection of each central city should be determined by its positioning of logistics industry, the creation of industrial development environment based on the construction of logistics service system and its advantages. Supply chain introduction program and policies and measures should be established according to logistics service industry so as to achieve industry clustering and whole industrial chain cultivation of the selected industry. Meanwhile, it is required to form industry clustering of Economic Belt of Silk Road and develop logistics service industry system with appreciation.

Industry clustering of Economic Belt of Silk Road. It is required to respond to the call of west development and develop towards the direction of industry clustering in central cities of Economic Belt of Silk Road with the impelling action of logistics hub cities, drive domestic and foreign economic and industrial resources to enter the international market based on high-efficiency and low-cost logistics service of logistics hub cities, form industrial cluster development ability in central cities, advocate the reception of industrial transfer from eastern regions and conduct deep processing 
of resource products with unique re sources in the region so as to extend the industrial chain of existing competitive industries and drive logistics industry to the path of professional and large-scale industry clustering, develop western international market with the radiation and service functions of logistics and cultivate international and competitive industry clustering in China based on international market demands.

Improvement of logistics industry in central cities of Economic Belt of Silk Road. In the construction of central cities of Economic Belt of Silk Road, it is required to first construct logistics industry and logistics service system in central cities as they are prerequisite of industry clustering. Central cities of Economic Belt of Silk Road can support the construction of the whole economic belt. Therefore, central cities should accelerate the construction of logistics hub cities and seek for breakthrough points of logistics development based on modern logistics industry according to regional and international features of logistics service. To achieve existing objectives, the following should be done: first, establish a good policy environment, strengthen the cultivation and development of logistics industry and promote industry clustering development on this basis; second, create an industrial chain with clustering expansion capability cultivated with modern logistics service, which can not only serve logistics, but also help leaped development of modern logistics.

\section{Development planning of logistics industry on Economic Belt of Silk Road}

Distinctive logistics service system has formed in coastal port cities based on natural waterway connection and superior resource advantages. However, the construction of logistics system on Economic Belt of Silk Road is different from cluster development of logistics industry. It depends on the coordination of hub and nodes in logistics park and rational division of work of other hubs on traffic road, thus forming logistics industry belt and radiation service system with scale effect and channel effect. Moreover, the competition of cities in the development of logistics and relevant cities hinders the connection of logistics service system of Economic Belt of Silk Road. Therefore, it is necessary to strengthen the cooperation of central cities along Economic Belt of Silk Road.

First, plan the construction of logistics park uniformly. The construction of "Economic Belt of Silk Road" is a national economic development strategy put forward by the Chinese government in the initial stage of this century as well as an extension of achievements of reform and opening up. This practice will inject unlimited vigor into the backward western and central economy. Therefore, there must be a high starting point and standard in logistics development planning of Economic Belt of Silk Road. It should be implemented according to the economic strategic level of national western development. It is required to establish orientation standard based on development demands of the whole economic belt, develop logistics hub into a national internationalized transfer station with strong resource integration, high service efficiency and low cost according to the advancing development and planning of hub and node in logistics park on the Economic Belt and logistics hub base with western development platform function, create a uniform and integrated modern logistics service market and improve network facilities of transport corridors on the Economic Belt so as to accelerate the construction of logistics system of Economic Belt of Silk Road.

Second, plan traffic corridors on Economic Belt of Silk Road. It is commonly said that "road construction is key in economic development”. With western development today, smooth traffic will facilitate economic development. Therefore, the planning of traffic corridor on Economic Belt of Silk Road should be implemented according to industrial distribution, cooperative development direction and the layout of logistics hub and node. In addition, it is necessary to optimize corridor distribution planning, make the construction and development of corridors adaptive with existing corridor functions and form the support of economic development by inland corridors. In terms of industrial distribution, it is required to cooperate with international economy and develop traffic corridor on Economic Belt of Silk Road into modern facilities with comprehensively improved functions and rational layout.

Third, improve regional coordination mechanism. The planning and construction of Economic Belt of Silk Road is a rare great act in the history of China, which symbolizes the strength of China and wise planning of the leadership.However, the construction of logistics system on Economic Belt 
of Silk Road involves many provinces. To establish a uniform service market and integrated service system, trans-regional operation of logistics service is required. Due to factors such as industrial development, international trade in goods, service trace and transit logistics organization, it is inevitable to establish an effective coordination mechanism. Therefore, the government should come forward and prepare for the construction of logistics development coordination organization of Economic Belt of Silk Road.

Forth, accelerate the development of multimodal transport. Uniform logistics supply chain system pursues for high efficiency and low cost. Therefore, it is required to implement multimodal transport system mainly involving railway transportation supplemented by other transportation means based on the function of traffic corridor and comprehensive transportation junction and existing railway resources. To adapt to demands of the construction of logistics leading industrial chain and industry clustering development, it is necessary to innovate development policies and mode of multimodal transport.

Fifth, innovate development policies. Basic policy for the construction of Economic Belt of Silk Road: each central city should implement the construction of international regional logistics hub with the principle of construction of logistics service system covering economic belt. When innovating policies for logistics industry, it is required to consider the improvement of competitive capacity for participating in domestic and foreign economic and industrial development, break through traditional taxation, fiscal and land policies and seek for new policies good for the construction of industrial chain and industry clustering development led by logistics service, such as new policies of free trade zone centering on negative list management, new policies that can cultivate goods development ability with international competitiveness and new policies for the construction of logistics service system that can integrate regional international resources.

\section{Conclusion}

In conclusion, Chinese practice of creating "Economic Belt of Silk Road" is a great plan for catering for international situation, exploring domestic potentials and developing the Chinese national vigorously. The implementation of this strategy can provide development opportunities for broad inland areas, especially western regions in China. Coastal cities in China have set an example for the development of inland cities through reform and opening up and summarized experience that can be used for reference, i.e. cater for modern service industry to drive manufacturing and business industries and finally form industrial chain and industry clustering scale. To develop inland and western regions, it is first required to develop with modern logistics industry, achieve a higher starting point and stronger radiating capacity through logistics, build a modern industrial development chain of Economic Belt of Silk Road on this basis and make contributions to the development of Chinese international trade.

\section{References}

[1] Wang Haiyun, Zhao Changqing and Li Jianmin et al. Background, Potential Challenges and Future Trend of Conception of “Economic Belt of Silk Road”. Euro-Asia Economy, 2014,(04):56-58.

[2] Sun Dan, Tan Qinlan. Study on Problems and Strategies of International Logistics Development in China under Background of Low-carbon Economy. China Commercial Forum, 2015,(07):88-90.

[3] Uratuh Lahmbel, Yelan Kduzi. Study on Development of International Logistics Industry in Xinjiang under Background of Strategic Concept of "Economic Belt of Silk Road". Logistics Engineering and Management, 2015,(05):5-6.

[4] Yelan Kduzi. Study on Countermeasures for International Logistics Development in Xinjiang Bonded Area under Normal State of “Economic Belt of Silk Road”. China Logistics and Procurement, 2015,(13):68-69. 
[5] Liang Xiaoli. Exploration and Analysis on Role of Bonded Logistics Center in Western Regions in International Trade - from Perspective of New Silk Road. China Business Information (Economic Theory Research), 2014,(14):83-84. 